\title{
Valor Nutritivo de Silagens de Sorgo ${ }^{1,2}$
}

\section{Viviane Glaucia de Souza ${ }^{3}$, Odilon Gomes Pereira ${ }^{4}$, Salete Alves de Moraes ${ }^{5}$, Rasmo Garcia ${ }^{4}$, Sebastião de Campos Valadares Filho ${ }^{4}$, Cláudio Prates Zago ${ }^{6}$, Eduardo Villela Villaça Freitas ${ }^{5}$}

RESUMO - Foram avaliados os consumos e as digestibilidades aparentes dos nutrientes de silagens de sorgo dos híbridos AG2006, AGX215, AGX213, AGX202 e AG2002. Utilizaram-se 20 carneiros adultos, sem raça definida, castrados, com peso médio de 50,7 kg, distribuídos EM um delineamento em blocos casualizados, com quatro animais por tratamento. Não houve diferença significativa entre as silagens para o consumo dos diversos nutrientes. Os consumos de matéria seca e nutrientes digestíveis totais expressos em g/dia revelaram valores variando de 936,2 (AGX202) a 1156,4 (AG2006) e de 460,9 (AGX215) a 613,4 (AGX213), respectivamente. Os coeficientes de digestibilidade diferiram entre as silagens, registrando-se maiores coeficientes de digestibilidade aparente da matéria seca e da matéria orgânica para a silagem do híbrido AGX213, em relação às silagens dos híbridos AGX215, AG2006 e AG2002. Com base nos consumos e digestibilidades dos nutrientes, excetuando proteína bruta, os híbridos AGX 213e AGX202 mostraram-se promissores para a produção de silagem.

Palavras-chave: consumo, digestibilidade aparente, ovinos

\section{Nutritive Value of Sorghum Silages}

\begin{abstract}
The intake and apparent digestibility of silage nutrients of different sorghum hybrids: AG2006, AGX215, AGX213, AGX202 e AG2002, were evaluated. Twenty crossbred castrated sheep, averaging $50.7 \mathrm{~kg}$, were assigned to a randomized blocks design, with four animals per treatment. There was no significant difference among silages for the different nutrients intake. Dry matter and total digestible nutrients intakes, in g/day, showed values that ranged from 936.2 (AGX202) to 1156.4 (AG2006) and from 460.9 (AGX215) to 613.4 (AGX213), respectively. The coefficients of digestibility showed differences among silages, and the higher coefficients of apparent dry matter and organic matter digestibility were recorded for the silage of AGX213 hybrid, compared to the silages of AGX215, AG2006 and AG2002 hybrids. Based on the intake and digestibility of the nutrients, except for the crude protein content, the AGX213 and AGX202 were successful for silage production.
\end{abstract}

Key Words: intake, apparent digestibility, sheep

\section{Introdução}

No Brasil, devido à estacionalidade de produção das pastagens e à intensificação dos sistemas de produção, o uso de silagem de sorgo vem crescendo a cada ano, principalmente em regiões áridas e semi-áridas, onde a cultura se sobressai, por sua maior resistência ao estresse hídrico. O Brasil, segundo Zago (1991), é um dos países com maiores potencialidades de adaptação e crescimento da cultura de sorgo no mundo.

O uso da cultura de sorgo para silagem, no Brasil, surgiu a partir da introdução de variedades de porte alto, com alta produtividade de massa verde. Preocupava-se naquele momento apenas com a redução do custo da tonelada de matéria verde de silagem produ- zida, sem considerar a qualidade deste material. Entretanto, com o passar do tempo, os produtores passaram a exigir um material com maior produção de nutrientes por unidade de área. Isso explica porque muitas vezes um sorgo forrageiro pode ser preferido a um granífero, pois, apesar de possuir valor nutritivo geralmente inferior, apresenta alta produção, o que pode resultar em maior produção de nutrientes por unidade de área (Nussio \& Manzano, 1999). Assim, com o desenvolvimento de machos estéreis de sorgo, permitiu-se a produção de híbridos mais apropriados para a confecção de silagem, não apenas com boa produtividade de matéria seca, mas também com alto valor nutritivo. Estes novos materiais genéticos precisam ser avaliados pelas instituições de pesquisa

\footnotetext{
${ }^{1}$ Parte da tese de mestrado do primeiro autor, apresentada ao Programa de Pós-Graduação em Zootecnia da Universidade Federal de Viçosa-UFV, bolsista da Capes,

${ }^{2}$ Convênio no194/98-UFV/FUNARBE/Sementes Agroceres S.A.

${ }^{3}$ Doutoranda em Zootecnia/UFV. Av. P.H. Rolfs s/nº, Viçosa-MG, 36571-000. E.mail: vivisouza@yahoo.com

${ }^{4}$ Prof. do Dpto. de Zootecnia/UFV, bolsista do CNPq.

${ }^{5}$ Mestrando em Zootecnia/ UFV.

${ }^{6}$ Eng. Agrônomo, MSC., Pesquisador da Dow-Agroscience.
} 
para que produtores e técnicos possam ser orientados na escolha do material para ensilagem.

A avaliação do valor nutritivo da silagem é melhor interpretada pela resposta do consumo voluntário, digestibilidade e eficiência da utilização de nutrientes digeridos (Elizalde, 1995). O consumo voluntário é empregado para designar o limite máximo do apetite (Thiago \& Gill, 1990), sob condições de alimentação ad libitum, e constitui-se em importante critério na formulação de dietas para bovinos leiteiros e de corte, no cálculo da área necessária para pastagens em sistemas extensivos e semi-intensivos, para o estabelecimento de culturas para a ensilagem, bem como para o controle de estoques de alimentos. Isto significa que o grau de exatidão de suas estimativas possui importância capital (NRC, 1989; Mertens, 1992).

Condições precárias de ensilagem que favorecem uma fermentação clostridiana produzem silagens com características de baixo consumo. Os produtos que deprimem o consumo incluem amônia e ácidos voláteis, particularmente o acético (Forbes, 1995).

A digestibilidade do alimento, basicamente, é a sua capacidade de permitir que o animal utilize os seus nutrientes em maior ou menor escala. Essa capacidade é expressa pelo coeficiente de digestibilidade do nutriente, sendo uma característica do alimento, e não do animal (Coelho da Silva \& Leão, 1979).

Existe grande variação entre os dados referentes ao consumo e à digestibilidade aparente em ovinos alimentados com silagem de sorgo. Segundo Pereira et al. (1993), estas variações se devem, em parte, ao grande número de variedades existentes, associadas a outros fatores, como local de plantio, época de plantio, idade de corte, época de corte, densidade de plantas, entre outros, o que provocará também grande diferença na qualidade das silagens.

Tonani (1995), avaliando o valor nutritivo de silagens de três híbridos de sorgo (forrageiro, duplopropósito e granífero), colhido em três estádios de maturação de grãos (leitoso, pastoso e farináceo), verificou maior consumo de matéria seca para a silagem do híbrido de duplo propósito no estádio leitoso. $\mathrm{O}$ autor recomenda que os cortes sejam efetuados em estádio de maturação de grão leitoso a pastoso, pois há redução na digestibilidade da matéria seca em estádios mais avançados. Entretanto, Andrade \& Carvalho (1992) verificaram as maiores ingestões diárias de matéria seca e nutrientes digestíveis totais (NDT) quando os grãos estavam nos estádios farináceos a duros.
Híbridos de sorgo no estádio de grão leitoso normalmente apresentam maiores coeficientes de digestibilidade da porção fibrosa. No entanto, o rápido aumento da porção de grãos e, conseqüentemente, de amido altamente digestível que ocorre com o amadurecimento compensa a diminuição da digestibilidade da porção fibrosa, mantendo inalterada a digestibilidade da matéria seca (Zago, 1999).

O objetivo deste trabalho foi avaliar o consumo e a digestibilidade dos nutrientes das silagens dos híbridos AG 2006, AGX 215, AGX 213, AGX 202 e AG 2002, em ovinos.

\section{Material e Métodos}

O trabalho foi conduzido no Laboratório de Animais do Departamento de Zootecnia da UFV, no mês de maio de 1998, no município de Viçosa, Minas Gerais. Foram utilizados 20 carneiros adultos, sem raça definida, castrados, com peso médio de $50,7 \mathrm{~kg}$, distribuídos em um delineamento em blocos casualizados, de acordo com o peso, com quatro animais por tratamento. Os animais foram pesados no início e no final do experimento. Após a primeira pesagem, por sorteio, efetuou-se a distribuição dos animais nos tratamentos, fazendo-se em seguida a vermifugação dos mesmos. Os animais ficaram alojados em gaiolas de metabolismo, providas de bebedouro e cochos para fornecimento das silagens e de mistura mineral. Para a coleta de fezes, foram usadas sacolas especiais de napa, adaptadas aos animais.

Neste ensaio, foram avaliadas as silagens dos seguintes híbridos forrageiros: AG 2006, porte médio (2,20 a 2,40 m), colmo seco, ciclo médio e população recomendada de 140.000 plantas por hectare; AG 2002, porte alto (altura média de $3 \mathrm{~m}$ ), ciclo médio (105 a 110 dias em regiões tropicais), colmo suculento e população recomendada de 125.000 plantas por hectare; AGX 215, porte médio/alto, ciclo médio, colmo seco e população recomendada de 150.000 plantas por hectare; AGX 213, porte alto, ciclo médio, colmo seco e população recomendada de 125.00 plantas por hectare; e AGX 202, porte alto, ciclo médio, colmo seco e população recomendada de 125.00 plantas por hectare. Os dois primeiros são híbridos comerciais e os três últimos, híbridos em fase experimental e, portanto, ainda não se encontram disponíveis no mercado, excetuando-se o AGX 213, lançado recentemente, com nome comercial VOLUMAX. Todos os híbridos foram cultivados nas 
dependências da Central de Experimentação e Pesquisa do Triângulo Mineiro - CEPET, da Universidade Federal de Viçosa (UFV), respeitando-se as recomendações de plantio do fabricante de sementes. Em função da análise de solo e com base na recomendação obtida pelo método do $\mathrm{AP}^{3+}, \mathrm{Ca}^{2+} \mathrm{e} \mathrm{Mg}^{2}$ (Comissão de Fertilidade do Solo do Estado de Minas Gerais - Cfsemg, 1989), foram incorporados $400 \mathrm{~kg} / \mathrm{ha} \mathrm{de}$ calcário $(\mathrm{PRNT}=75 \%)$ ao solo. O preparo do solo constituiu de uma aração e duas gradagens. A adubação recomendada constituiu-se de $350 \mathrm{~kg} / \mathrm{ha}$ da fórmula (NPK) 06-28-08 no plantio, mais $350 \mathrm{~kg} / \mathrm{ha}$ de sulfato de amônia em cobertura, dividida em duas parcelas iguais.

A confecção das silagens foi feita em barris de plástico de aproximadamente $100 \mathrm{~kg}$ de capacidade, quando os grãos atingiram o estádio farináceo duro, sendo posteriormente transportadas para Viçosa, para condução deste ensaio.

O ensaio teve duração de 21 dias, sendo 15 para adaptação dos animais às dietas e gaiolas e seis para coletas. As silagens foram fornecidas diariamente as 8 e $16 \mathrm{~h}$ durante todo o período experimental.

A quantidade de silagem fornecida a cada animal, na fase de coletas, foi $10 \%$ superior ao consumo médio diário observado na fase preliminar, de modo a possibilitar sobras. Nesta fase, foram retiradas amostras diárias para elaboração de uma amostra composta das silagens fornecidas e das sobras por animal, as quais foram acondicionadas em sacos plásticos devidamente identificados e guardadas em freezer para análises posteriores.

A coleta de fezes foi feita diariamente as 7 e $17 \mathrm{~h}$, registrando-se, nessa oportunidade, a quantidade de fezes excretada por animal. Após homogeneização do material, foi retirada uma alíquota diária em torno de 5 a $10 \%$ para confecção de uma amostra composta por animal. As amostras de fezes foram colocadas em sacos plásticos, identificadas e guardadas em freezer, para análises posteriores. Estas amostras, juntamente com as amostras das silagens e sobras, foram submetidas à pré-secagem a $65^{\circ} \mathrm{C}$, por 72 horas. Após foram processadas em moinho de faca tipo "Willey", com peneira de $1 \mathrm{~mm}$ e armazenadas em recipientes de vidro com tampa de polietileno, para análises laboratoriais.

As análises de matéria seca (MS), proteína bruta (PB), fibra em detergente neutro (FDN), extrato etéreo (EE) e matéria orgânica (MO) foram realizadas conforme procedimentos descritos por Silva
(1990). Os carboidratos totais (CT) e os nutrientes digestíveis totais (NDT) foram calculados segundo metodologia da Universidade de Cornell, descrita por Sniffen et al. (1992), em que CT(\%) $=100-(\%$ PB + $\% \mathrm{EE}+\%$ Cinzas $)$ e NDT $(\mathrm{g} / \mathrm{dia})=(\mathrm{gPB}$ ing. $-\mathrm{gPB}$ fecal $)+2.25$ (gEE ing. - gEE fecal $)+(g C T$ ing. - gCT fecal), sendo ing $=$ ingerido.

Os dados foram submetidos à análise de variância e suas médias, comparadas pelo teste Tukey, em nível de 5\% de probabilidade, utilizando-se o Sistema de Análise Estatística (Saeg), versão 8.0, desenvolvido pela Universidade Federal de Viçosa - UFV (2000).

\section{Resultados e Discussão}

A composição bromatológica das silagens encontra-se na Tabela 1. Observa-se que o teor de matéria seca variou de 23,2 (AG 2002) a 38,5\% (AG 2006). Pereira (1991), avaliando silagens de sorgo de portes alto (AG 2002), médio (AG 2004E) e baixo (AG $2005 \mathrm{E})$, também registrou menor teor de matéria seca $(23,6 \%)$ para a silagem do híbrido AG 2002. Isto pode estar associado ao caráter suculento do colmo deste híbrido. Todavia, o menor teor e MS no momento da ensilagem não influenciou negativamente a qualidade do processo fermentativo, o que pode ser explicado pelo seu elevado teor de carboidratos solúveis (19,80\% na MS) (Gontijo Neto, 2000).

Os teores médios de matéria orgânica das silagens variaram de 95,7 (AGX 215) a 96,3\% (AGX 202). Estes valores encontram-se ligeiramente superiores aos teores de 94,1 e 93,4\% observados por Pereira et al. (1993) para híbridos de porte alto e médio, respectivamente.

Para a proteína bruta os teores foram próximos entre as silagens, excetuando-se o do híbrido AGX 202 , que revelou valor numericamente inferior $(5,7 \%)$. Segundo Zago (1991), os híbridos de porte baixo e médio têm apresentado teores de proteína bruta superiores aos de porte alto, devido à maior participação de folhas, panículas e grãos na massa ensilada. Cândido et al. (1999) também não detectaram diferenças $(\mathrm{P}>0,05)$ entre a proteína bruta das silagens dos híbridos AG 2002, AGX 202, AGX 213 e AGX 215 , que apresentaram valores de 6,$30 ; 6,98 ; 6,47$; e $6,95 \%$, respectivamente.

Os teores médios de extrato etéreo e de carboidratos totais foram semelhantes entre as silagens apresentando valores médios de 2,0 e 87,6\%, respectivamente.

Quanto ao teor de fibra em detergente neutro das 
Tabela 1 - Teores médios de matéria seca (MS), matéria orgânica (MO), proteína bruta (PB), extrato etéreo (EE), carboidratos totais (CT), fibra em detergente neutro (FDN) e nutrientes digestíveis totais (NDT), obtidos para as diferentes silagens

Table 1 - Average contents of dry matter (DM), organic matter (OM), crude protein (CP), ether extract (EE), total carbohydrates (TC), neutral detergent fiber (NDF) and total digestible nutrients (TDN) obtained for the different silages

\begin{tabular}{lccccccc}
\hline & \multicolumn{5}{c}{$\begin{array}{c}\text { Frações na MS (\%) } \\
\text { Fractions (\% of DM) }\end{array}$} \\
\cline { 2 - 7 } Silagens & MS (\%) & MO & PB & EE & CT & FDN & NDT \\
Silages & $D M(\%)$ & OM & $C P$ & $E E$ & $T C$ & NDF \\
\hline AG 2006 & 38,5 & 96,0 & 6,5 & 1,9 & 87,6 & 63,4 \\
AGX 215 & 30,7 & 95,7 & 6,2 & 2,0 & 87,5 & 61,6 \\
AGX 213 & 35,0 & 96,0 & 6,4 & 2,1 & 87,5 & 64,4 & 57,8 \\
AGX 202 & 33,9 & 96,3 & 5,7 & 2,1 & 88,5 & 65,0 & 53,9 \\
AG 2002 & 23,2 & 95,8 & 6,8 & 2,0 & 87,0 & 60,1 \\
\hline
\end{tabular}

silagens, registraram-se valores variando de 60,1 (AG 2002) a 65,0\% (AGX 202). Estes valores se encontram dentro da faixa registrada pela literatura, para híbridos de sorgo. Cândido et al. (1999) não encontraram diferenças $(\mathrm{P}>0,05)$ entre os teores de FDN das silagens dos híbridos AG 2002, AGX 202, AGX 213, AGX215 e AG 2005E, cujos valores variaram de 61,5 a $69,5 \%$.

Os teores médios de nutrientes digestíveis totais variaram de 46,9 (AGX 215) a 57,8\% (AGX 213). Valadares Filho et al. (2001) apresentam valor médio de nutrientes digestíveis totais para silagem de sorgo de $53,5 \%$.

Gontijo Neto (2000) verificou produções de matéria seca total de 14,6; 16,7; 16,2 e 18,7 t/ha para os híbridos AGX 215; AGX 213; AGX 202 e AG 2002, respectivamente, em condições semelhantes à deste experimento. Para o híbrido AG 2006 há relatos de produção de matéria seca total de 11,2 t/ha (Silva et al., 1997).

Os consumos médios diários de matéria seca, matéria orgânica, proteína bruta, extrato etéreo, carboidratos totais, fibra em detergente neutro e nutrientes digestíveis totais das silagens não diferiram entre si ( $\mathrm{P}>0,05)$, conforme se observa na Tabela 2.

Para o consumo de matéria seca expresso em $\mathrm{g} / \mathrm{kg}^{0,75}$ os valores variaram de 53,6 (AGX 202) a 66,7 (AG 2006). A tendência de maior consumo da silagem do híbrido AG 2006 pode decorrer de seu teor de matéria seca mais elevado (Tabela 1), uma vez que o consumo aumenta com o incremento do teor de matéria seca do alimento (Lahr et al., 1983; Pereira et al., 1993; e Pimentel et al., 1997) e a proporção de grãos é responsável pela maior elevação no teor de matéria seca da massa ensilada, em função do seu menor conteúdo de água (Vilela, 1985). Estudos conduzidos por Zanotelli et al. (1998), com diferentes híbridos de sorgo, apresentaram maior proporção de grãos para o híbrido AG 2006 (45,9\%). Para os híbridos AGX 215; AGX 213; AGX 202 e AG 2002, Gontijo Neto (2000) verificaram 38; 36; 39 e 29\% de panícula na matéria seca total. Em ensaio com ovinos, Pereira (1991) encontrou valores de consumo de matéria seca de 63,3; 81,7; e 74,6 g MS/ $\mathrm{kg}^{0,75}$, respectivamente, para os híbridos AG 2002 (porte alto), AG 2004E (porte médio) e AG 2005E (porte baixo).

Tonani (1995), trabalhando com silagens de três híbridos de sorgo (forrageiro, duplo-propósito e granífero), verificou maior consumo $\left(62,4 \mathrm{~g} \mathrm{MS} / \mathrm{kg}^{0,75}\right.$ ) para a silagem do híbrido de duplo propósito, em relação ao granífero e forrageiro, que apresentaram, respectivamente, consumos de 59,2 e 50,6 g MS/kg 0,75 . Condições precárias de ensilagem que favorecem uma fermentação clostridiana produzem silagens com características de baixo consumo. Os produtos que deprimem o consumo incluem amônia e ácidos voláteis, particularmente o acético (Forbes, 1995). Cândido et al. (2002) não verificaram diferenças entre os teores de ácido acético, ácido lático, pH e N-amoniacal, para as silagens dos híbridos AGX 215; AGX 213; AGX 202 e AG 2002. Tal fato justificaria a similaridade entre os consumos das diferentes silagens.

Os consumos médios de matéria orgânica não apresentaram diferenças $(\mathrm{P}>0,05)$ entre os híbridos estudados, apresentando comportamento semelhante àquele verificado para o consumo de matéria seca, com valores de 1110,3; 941,5; 1018,8; 901,4; e 960,3 g/dia para as silagens dos híbridos AG 2006, AGX 215, AGX 213, AGX 202 e AG 2002, respectivamente.

Para os consumos médios de proteína bruta, extrato etéreo e carboidratos totais, não se verificaram dife- 
Tabela 2 - Consumos médios diários de matéria seca, matéria orgânica, proteína bruta, extrato etéreo, carboidratos totais, fibra em detergente neutro e nutrientes digestíveis totais de silagens de sorgo em ovinos

Table 2 - Average daily intakes of dry matter, organic matter, crude protein, ether extract, total carbohydrates, neutral detergent fiber and total digestible nutrients of sorghum silages of sheep

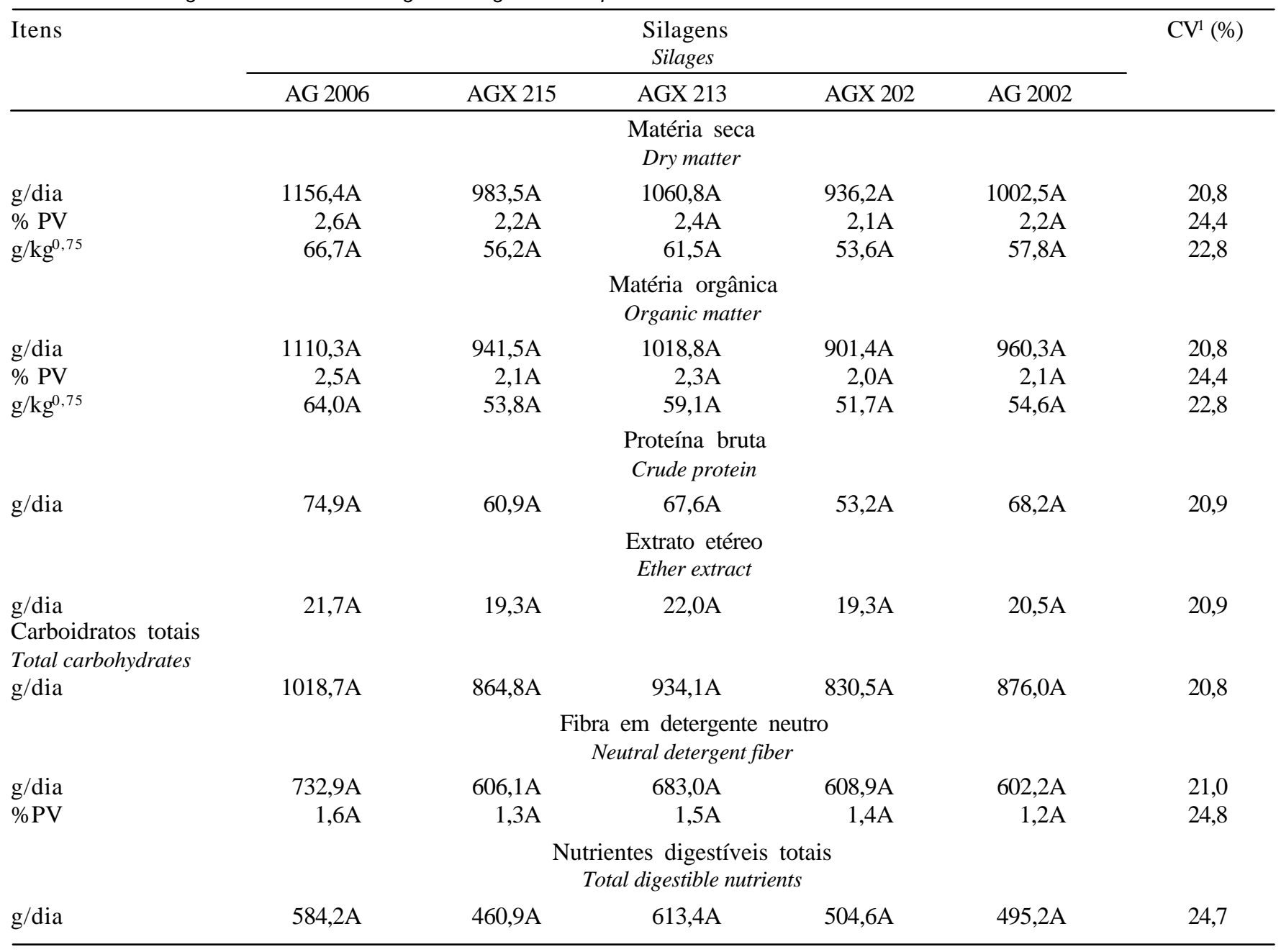

Médias seguidas de letras iguais, na mesma linha, não diferem $(P>0,05)$ pelo teste Tukey.

Means followed by same letter in a row, are not different $(P<.05)$ by Tukey test.

${ }^{1}$ Coeficiente de variação (Coefficient of variation).

renças $(\mathrm{P}>0,05)$, o que se deve ao fato da semelhança entre a composição bromatológica das silagens.

O consumo de fibra em detergente neutro (FDN), expresso em porcentagem do peso vivo, que variou de 1,32 (AG 2002) a 1,64\% (AG 2006), também não diferiu $(\mathrm{P}>0,05)$ entre as silagens. Isto pode estar associado ao fato de as silagens terem apresentado teores de FDN muito próximos (Tabela 1), uma vez que não se detectaram diferenças entre o consumo da matéria seca das silagens (Tabela 2).

Também não se detectaram diferenças $(\mathrm{P}>0,05)$ para o consumo de nutrientes digestíveis totais entre as silagens dos híbridos avaliados (Tabela 2). Numericamente o maior consumo para a silagem do híbrido AGX 213 pode decorrer do seu conteúdo mais elevado de NDT, conforme se verifica na Tabela 1, uma vez que não ocorreram diferenças no consumo de matéria seca entre as silagens.

Os coeficientes médios de digestibilidade dos nutrientes estão apresentados na Tabela 3. Os coeficientes de digestibilidade aparente da matéria seca e da matéria orgânica foram maiores $(\mathrm{P}<0,05)$ para a silagem do híbrido AGX 213 em relação às silagens dos híbridos AGX 215, AG 2006 e AG 2002. O valor médio observado para o coeficiente de digestibilidade da matéria seca da silagem do híbrido AGX 213 foi superior aos encontrados por Black et al. (1980) e Tonani (1995) com silagens de híbridos forrageiros.

As panículas apresentam grande conteúdo de amido, que é altamente digestível. Assim, poder-se-iam espe- 
Tabela 3 - Coeficientes médios de digestibilidade aparente de matéria seca (MS), matéria orgânica (MO), proteína bruta $(P B)$, extrato etéreo (EE), carboidratos totais (CT) e fibra em detergente neutro (FDN) de silagens de sorgo em ovinos

Table 3 - Average apparent digestibilities of dry matter (DM), organic matter (OM), crude protein (CP), ether extract (EE), total carbohydrates (TC) and, neutral detergent fiber (NDF) of sorghum silages of sheep

\begin{tabular}{lcccccc}
\hline Silagens & \multicolumn{5}{c}{$\begin{array}{c}\text { Digestibilidade aparente (\%) } \\
\text { Apparent digestibility (\%) }\end{array}$} \\
\cline { 2 - 7 } & $\mathrm{MS}$ & $\mathrm{MO}$ & $\mathrm{PB}$ & $\mathrm{EE}$ & $\mathrm{CT}$ & FDN \\
& $D M$ & $O M$ & $C P$ & $E E$ & $T C$ & $N D F$ \\
\hline AG 2006 & $51,4 \mathrm{~B}$ & $53,3 \mathrm{~B}$ & $40,7 \mathrm{BC}$ & $72,3 \mathrm{AB}$ & $54,1 \mathrm{~B}$ & $43,3 \mathrm{~B}$ \\
AGX 215 & $50,2 \mathrm{~B}$ & $52,5 \mathrm{~B}$ & $37,5 \mathrm{C}$ & $67,8 \mathrm{~B}$ & $53,5 \mathrm{AB}$ & $41,0 \mathrm{~B}$ \\
AGX 213 & $63,7 \mathrm{~A}$ & $64,9 \mathrm{~A}$ & $53,4 \mathrm{~A}$ & $76,5 \mathrm{~A}$ & $65,7 \mathrm{~A}$ & $58,8 \mathrm{~A}$ \\
AGX 202 & $58,3 \mathrm{AB}$ & $59,5 \mathrm{AB}$ & $39,5 \mathrm{C}$ & $74,0 \mathrm{~A}$ & $60,6 \mathrm{AB}$ & $51,6 \mathrm{AB}$ \\
AG 2002 & $53,1 \mathrm{~B}$ & $55,8 \mathrm{~B}$ & $49,3 \mathrm{AB}$ & $71,5 \mathrm{AB}$ & $55,3 \mathrm{~B}$ & $40,8 \mathrm{~B}$ \\
CV(\%) & 7,1 & 6,5 & 9,7 & 3,5 & 7,4 & 11,4 \\
\hline
\end{tabular}

Médias seguidas de letras iguais, na mesma linha, não diferem $(P>0,05)$ pelo teste Tukey.

Means followed by same letter in a row, are not different $(P<.05)$ by Tukey test.

${ }^{1}$ Coeficiente de variação (Coefficient of variation).

rar maiores coeficientes de digestibilidade da matéria seca na silagem do híbrido AG 2006, pois este apresenta maior proporção de panículas entre os híbridos avaliados (Silva et al., 1997; Zanoteli et al., 1998 e Gontijo Neto, 2000). Entretanto, segundo Cummins (1972), não apenas as proporções das diferentes partes da planta definem uma silagem de alto valor nutritivo, mas também a digestibilidade de partes individuais da planta tem influência sobre sua digestibilidade total.

Silva et al. (1997), trabalhando com híbridos AG 2006 e BR 303, observaram maior digestibilidade in vitro da matéria seca para a silagem do híbrido $\mathrm{AG}$ 2006, embora tenha apresentado menor proporção de panícula na matéria seca total. No entanto, Cummins (1972), em estudos com quatro híbridos de sorgo com diferentes porcentagens de colmos, folhas e panículas, relatou que a digestibilidade das panículas é sempre maior que a das folhas e, além disso, os colmos são as partes de menor digestibilidade.

Em relação à proteína bruta, observou-se maior digestibilidade para o híbrido AGX 213, que não diferiu $(\mathrm{P}>0,05)$ do híbrido AG 2002. Cândido (2000) não verificou diferenças entre os teores médios de nitrogênio insolúvel em detergente ácido (NIDA) para as silagens dos híbridos AG 2006, AGX 215, AGX 213, AGX 202 e AG 2002.

Para os coeficientes de digestibilidade do extrato etéreo, o híbrido AGX215 mostrou-se inferior em relação aos demais, mas não diferindo $(\mathrm{P}>0,05)$ dos híbridos AG 2006 e AG 2002. Já para os coeficientes de digestibilidade dos carboidratos totais, o híbrido AGX 213 foi superior, porém não diferiu $(\mathrm{P}>0,05)$ dos híbridos AGX 215 e AGX 202.

A digestibilidade aparente da fibra em detergente neutro apresentou comportamento semelhante àquele verificado para a matéria seca, registrando-se valores mais elevados para as silagens dos híbridos AGX 213 e AGX 202, que, por sua vez, não diferiram $(\mathrm{P}>0,05)$ entre si (Tabela 3$)$.

A melhoria da qualidade nutricional de um híbrido deve-se mais ao aumento na digestibilidade da fibra do que às diferenças na proporção de grãos na planta inteira (Hunt et al., 1993). De fato, existe acentuada variação na relação colmo:folha:panícula, entre os diferentes híbridos, o que sugere a possibilidade de se melhorar o valor nutritivo, por meio da seleção de genótipos com melhor equilíbrio colmo, folha e panícula, bem como pela seleção de linhagens de maior digestibilidade dessas partes da planta (Zago, 1999).

\section{Conclusões}

Com base nos consumos e nas digestibilidades dos nutrientes, excetuando proteína bruta, os híbridos AGX 213 e AGX 202 mostraram-se promissores para a produção de silagem.

\section{Literatura Citada}

ANDRADE, J.B.; CARVALHO, D.D. Estádio de maturação na produção e qualidade da silagem de sorgo. II - Digestibilidade e consumo da silagem. Boletim da Indústria Animal, v.49, n.2, p.101-106, 1992.

BLACK, J.R.; ELY, O.L.; McCULLOUGH, E.M. et al. Effect of stage of maturity and silage additives upon the yield of gross and digestible energy in sorghum silage.Journal Animal Science, n.50, v.4, p.617-624, 1980. 
CÂNDIDO, M.J.D.; OBEID, J.A.; PEREIRA, O.G. et al. Avaliação da produção e do valor nutritivo de silagens de cinco híbridos de sorgo 1. FOR:056. In: REUNIÃO ANUAL DA SOCIEDADE BRASILEIRA DE ZOOTECNIA, 36., Porto Alegre, 1999. Anais...Viçosa, MG: Sociedade Brasileira de Zootecnia, 1999. p.35.

CÂNDIDO, M.J.D.; OBEID, J.A.; PEREIRA, O.G. et al. Características fermentativas e potencial biológico de silagens de híbridos de sorgo cultivados em doses crescentes de adubação. Revista Ceres, v.49, n.282, p.151-167, 2002.

CÂNDIDO, M.J.D. Qualidade e valor nutritivo de silagens de híbridos de sorgo(Sorghum bicolor (L.) Moench) sob doses crescentes de recomendação de adubação. Viçosa, MG: Universidade Federal de Viçosa, 2000. 57p. Dissertação (Mestrado em Zootecnia) - Universidade Federal de Viçosa, 2000.

COELHO DA SILVA, J.F., LEÃO, M.I. Fundamentos de nutrição de ruminantes. Piracicaba: Livroceres, 1979.380p.

COMISS ÃO DE FERTILIDADE DO SOLO DO ESTADO DE MINAS GERAIS - CFSEMG. Recomendações para uso de corretivos e fertilizantes em Minas Gerais. 4ํ-Aproximação. Lavras, 1989.

CUMMINS, D.G. Methods of evaluation and factors contributing to yield and digestibility of sorghum silage hybrids. In: ANNUAL CORN AND SORGHUM RESEARCH CONFERENCE, 27., 1972, London.Proceedings...London: Oxford, p.18-28, 1972.

ELIZALDE, H.F. El valor nutritivo de los ensilages. Revista Argentina Produccion Animal, v.15, n.1, p.103-121, 1995.

FORBES, J.M. Voluntary food intake and diet selection in farm animals. Wallington: CAB International, 1995. 532p.

GONTIJO NETO, M.M. Rendimento e valor nutritivo de híbridos de sorgo (Sorghum bicolor (L.) Moench) sob níveis crescentes de adubação. Viçosa, MG: Universidade Federal de Viçosa, 2000. 55p. Dissertação (Mestrado em Zootecnia) - Universidade Federal de Viçosa, 2000.

HUNT, C.W.; KEZAR, W.; HINMAN, D.D. et al. Effects of hybrid and ensiling with and without a microbial inoculant on the nutritional characteristics of whole-plant corn.Journal Animal Science, v.71, p.38-43.1993.

LAHR, D.A. ; OTTERBY, D.E. ; JOHNSON, D.G. et al. Effects of moisture content of complete diets on feed intake and milk production by cows. Journal of Dairy Science, v.66, n.8, p.1981-1900,1983.

MERTENS, D.R. Análise de fibra e sua utilização na avaliação e formulação de rações. In: SIMPÓSIO INTERNACIONAL DE RUMINANTES, REUNIÃO ANUAL DA SOCIEDADE BRASILEIRA DE ZOOTECNIA, 29., 1992, Lavras. Anais... Lavras: Sociedade Brasileira de Zootecnia, 1992. p.188-219.

NATIONAL RESEARCHCOUNCIL-NRC. Nutrientsrequirements of dairy cattle. 6.ed. Washington D.C., 1989. 159p.

NUSSIO, L.G.; MANZANO, R.P. Silagem de milho. In: SIMPÓSIO SOBRE NUTRIÇÃO DE BOVINOS: ALIMENTAÇÃO SUPLEMENTAR, 7, Piracicaba, 1999. Anais... Piracicaba: Fundação de Estudos Agrários "Luiz de Queiroz", 1999. p. 27-46.

PEREIRA, O.G. Produtividade do milho (Zea may L.), do sorgo (Sorghum bicolor(L.) Moench), da aveia (Avena Sativa), do milheto (Pennisetum americanum L.) e do híbrido (S.bicolor $\boldsymbol{x}$ S. sudanense) e respectivos valores nutritivos sob a forma de silagem e verde picado. Viçosa, MG: Universidade Federal de Viçosa, 1991. 86p. Dissertação (Mestrado em Zootecnia) - Universidade Federal de Viçosa, 1991.
PEREIRA, O.G.; OBEID, J.A.; GOMIDE, J.A.et al. Produtividade de uma variedade de milho (Zea mays L.) e de três variedades de sorgo (Sorghumbicolor (L.) Moench) e o valor nutritivo de suas silagens. Revista Brasileira de Zootecnia, v.22, n.1, p.31-38, 1993.

PIMENTEL, J.J.O.; SILVA, J.F.C.; VALADARES FILHO, S.C. et al.Efeito da suplementação protéica no valor nutritivo das silagens de milho e sorgo. In: REUNIÃO DA SOCIEDADE BRASILEIRA DE ZOOTECNIA, 34., Juiz de Fora, 1997. Anais... Juiz de Fora: Sociedade Brasileira de Zootecnia, 1997. p.184-186.

SILVA, D.J. Análise de alimentos: métodos químicos e biológicos. 2.ed. Viçosa, MG: Universidade Federal de Viçosa, 1990. 165p.

SILVA., J.M.; KICHEL, A.N.; THIAGO, L.R.L. et al. Avaliação de cultivares de milho e sorgo para a produção de silagem. In: REUNIÃO DA SOCIEDADE BRASILEIRA DE ZOOTECNIA, 34., 1997, Juiz de Fora.Anais... Juiz de Fora: SBZ, 1997. p.87-189.

SNIFFEN, C.J., O'CONNOR, J.D. VAN SOEST, P.J., FOX, D.J., RUSSSEL, J.B. A net carbohydrate and protein system for evaluating cattle diets. 11. Carbohydrate and protein availability. Journal Animal Science, v.70, n.11, p.35623577, 1992.

THIAGO, L.R.L.S., GILL, M. Consumo voluntário: fatores relacionados com a degradação e passagem da forragem pelo rúmen. Campo Grande: EMBRAPA-CNPGC. 1990. $65 \mathrm{p}$.

TONANI, F.L. Valor nutritivo das silagens de sorgo (Sorghum biocolor L.) em diferentes estágios de maturação dos grãos. Viçosa, MG: Universidade Federal de Viçosa, 1995. 56p. Dissertação (Mestrado em Zootecnia) - Universidade Federal de Viçosa, 1995.

UNIVERSIDADE FEDERAL DE VIÇOSA - UFV. 2000.SAEG - Sistema de análises estatísticas e genéticas. Versão 8.0. Viçosa, MG. 142p. (Manual do usuário).

VALADARES FILHO, S.C.; ROCHA JR., V.R.; CAPELLE, W.R. Tabelas brasileiras de composição de alimentos para bovinos. Viçosa, MG: Universidade Federal de Viçosa, 2001. 297p.

VILELA, D. Sistema de conservação de forragem. Coronel Pacheco, EMBRAPA/CNPGL, 1985. 15p. (Boletim de Pesquisa, 11).

ZAGO, C.P. Silagem de sorgo. In: SIMPÓSIO SOBRE NUTRIÇÃO DE BOVINOS: ALIMENTAÇÃO SUPLEMENTAR, 7., Piracicaba, 1999. Anais... Piracicaba: Fundação de Estudos Agrários "Luiz de Queiroz", 1999. p.47-68.

ZAGO, C.P. Cultura de sorgo para produção de silagem de alto valor nutritivo. In: SIMPOSIO SOBRE NUTRIÇÃO DE BOVINOS, 4., 1991, Piracicaba. Anais... Piracicaba: Fundação de Estudos Agrários “Luiz de Queiroz”, 1991. p.169-217.

ZANOTELLI, F.O.; FONTE, L.A.M.; CHIELLE, Z.G. et al. Avaliação de cultivares de sorgo para silagem em solo hidromórfico. 2. Composição bromatológica e qualidade química das silagens. In: REUNIÃO DA SOCIEDADE BRASILEIRA DEZOOTECNIA, 35., 1998, Botucatu.Anais... Botucatu: Sociedade Brasileira de Zootecnia, 1998. p.251-253.

Recebido em: 28/03/02 Aceito em: $05 / 11 / 02$ 